\title{
Gold Nanoparticle Mediated Multi-Modal CT Imaging of Hsp70 Membrane-Positive Tumors
}

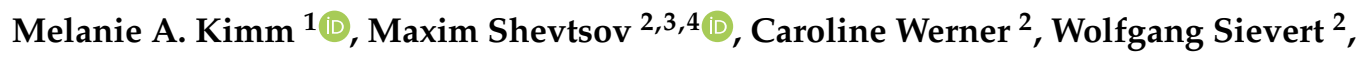 \\ Wu Zhiyuan ${ }^{2}$, Oliver Schoppe ${ }^{2,5}$, Bjoern H. Menze ${ }^{2,5}$, Ernst J. Rummeny ${ }^{1}$, Roland Proksa ${ }^{6}$, \\ Olga Bystrova ${ }^{4}$, Marina Martynova ${ }^{4}$, Gabriele Multhoff ${ }^{2}$ and Stefan Stangl $2, *$ iD \\ 1 Department of Diagnostic and Interventional Radiology, Klinikum rechts der Isar der Technischen \\ Universität München, 81675 Munich, Germany; Melanie.Kimm@tum.de (M.A.K.); \\ Ernst.Rummeny@tum.de (E.J.R.) \\ 2 Central Institute for Translational Cancer Research (TranslaTUM), Klinikum rechts der Isar der Technischen \\ Universität München, 81675 Munich, Germany; Maxim.Shevtsov@tum.de (M.S.); c.werner@tum.de (C.W.); \\ Wolfgang.Sievert@tum.de (W.S.); zhiyuan2012.wu@tum.de (W.Z.); Oliver.Schoppe@tum.de (O.S.); \\ Bjoern.Menze@tum.de (B.H.M.); Gabriele.Multhoff@tum.de (G.M.) \\ 3 Pavlov First Saint Petersburg State Medical University, 197022 St. Petersburg, Russia \\ 4 Institute of Cytology of the Russian Academy of Sciences (RAS), 194064 St. Petersburg, Russia; \\ o3608338@gmail.com (O.B.); mgmart14@mail.ru (M.M.) \\ 5 Institute for Advanced Studies, Department of Informatics, Technical University of Munich, \\ 85748 Garching, Germany \\ 6 Philips GmbH Innovative Technologies, Research Laboratories, 22335 Hamburg, Germany; \\ roland.proksa@philips.com \\ * Correspondence: Stefan.Stangl@tum.de; Tel.: +49-89-4140-6013; Fax: +49-89-4140-4299
}

Received: 15 April 2020; Accepted: 20 May 2020; Published: 22 May 2020

\begin{abstract}
Imaging techniques such as computed tomographies (CT) play a major role in clinical imaging and diagnosis of malignant lesions. In recent years, metal nanoparticle platforms enabled effective payload delivery for several imaging techniques. Due to the possibility of surface modification, metal nanoparticles are predestined to facilitate molecular tumor targeting. In this work, we demonstrate the feasibility of anti-plasma membrane Heat shock protein 70 (Hsp70) antibody functionalized gold nanoparticles (cmHsp70.1-AuNPs) for tumor-specific multimodal imaging. Membrane-associated Hsp70 is exclusively presented on the plasma membrane of malignant cells of multiple tumor entities but not on corresponding normal cells, predestining this target for a tumor-selective in vivo imaging. In vitro microscopic analysis revealed the presence of cmHsp70.1-AuNPs in the cytosol of tumor cell lines after internalization via the endo-lysosomal pathway. In preclinical models, the biodistribution as well as the intratumoral enrichment of AuNPs were examined $24 \mathrm{~h}$ after i.v. injection in tumor-bearing mice. In parallel to spectral CT analysis, histological analysis confirmed the presence of AuNPs within tumor cells. In contrast to control AuNPs, a significant enrichment of cmHsp70.1-AuNPs has been detected selectively inside tumor cells in different tumor mouse models. Furthermore, a machine-learning approach was developed to analyze AuNP accumulations in tumor tissues and organs. In summary, utilizing $\mathrm{mHsp} 70$ on tumor cells as a target for the guidance of cmHsp70.1-AuNPs facilitates an enrichment and uniform distribution of nanoparticles in mHsp70-expressing tumor cells that enables various microscopic imaging techniques and spectral-CT-based tumor delineation in vivo.
\end{abstract}

Keywords: gold nanoparticle; heat shock protein 70; molecular imaging; biomarker; spectral-CT 


\section{Introduction}

Detection of all malignant tumor cells in a patients' body is a prerequisite for a successful therapy outcome. In established clinical routine, combined positron emission tomography (PET)/computed tomography (CT) imaging is commonly used for tumors exceeding $0.5-1 \mathrm{~cm}^{3}$. For standard clinical PET imaging, ${ }^{18}$ F-glucose is often used as a PET tracer. However, glucose-based PET/CT imaging faces several disadvantages, such as false-positive and/or false-negative signals, e.g., triggered by the fact that only metabolically active but not resting cells can be visualized, the low tumor-to-background contrast, and the relatively low resolution of the technique [1]. With improved settings, a spatial resolution of $2 \mathrm{~mm}$ is technically feasible, as demonstrated in patients with prostate cancer [2].

The introduction of gold nanoparticles (AuNP)-based contrast agents added a new value to imaging techniques. Functionalization of novel metal-based nanoparticles with tumor-specific antibodies [3] and their utilization in imaging techniques such as photoacoustic tomography or CT combine the advantages of a molecular, tumor-specific imaging with the unique attributes of AuNP in clinical imaging. For instance, spectral-CT technology employs a photon-counting detector which registers the interactions of individual photons, creating a certain energy spectrum which can subsequently be converted into a color image. At the same time, a nonspectral attenuation image can be acquired. This combination allows a precise spatial information with a high resolution. With the emergence of clinical spectral-CT scanners, the need of tumor-specific contrast agents further increased. In this setting, AuNPs might play a crucial role as the energy-dependent X-ray attenuation properties (K-edge at $80.7 \mathrm{keV}$ ) allow an excellent separation from calcium (K-edge at $4 \mathrm{keV}$ ) and iodine (K-edge at $33.2 \mathrm{keV}$ ) [4].

For in vivo application, it is also essential that the applied nanoparticles are nontoxic, biodegradable or inert, and easily transportable in the blood and/or lymphatic system. Biocompatible camouflage of the NP surface is a prerequisite to avoid immediate uptake by macrophages. Small AuNPs $(<100 \mathrm{~nm})$ demonstrated to be beneficial for utilization in clinical applications [5-7]. Apart from the formulation of AuNPs, tumor imaging with nanoparticle-based contrast agents can be further improved and specified by functionalization with antibodies targeting tumor-specific, membrane-bound biomarkers. For an improved signal-to-background ratio and a high tumor specificity, candidate markers should be selectively expressed on tumor cells while being absent on healthy cells. Membrane-bound Heat shock protein 70 (Hsp70, Hsp70-1, HspA1A, \#3303) has been found to fulfill these criteria, exhibiting a remarkable tumor-specific targeting capability [8,9]. In addition to the physiological, cytosolic expression in all nucleated cells, Hsp70 is also found on the plasma membrane of malignantly transformed cells. Upon stress, this molecular chaperone has been found to be increased in the cytosol and on the plasma membrane of different murine and human tumor cells. Screening of tumor biopsies of over 1200 patients has shown that the majority of the primarily diagnosed carcinoma samples but none of the tested corresponding normal tissues exhibited a membrane Hsp70-positive phenotype [10-13]. After therapy of tumors with standard regimens, such as radiotherapy or chemotherapy, the membrane expression density of Hsp70 on tumor cells is increased [14], which in turn further improves targeting of membrane Hsp70-positive tumors after standard therapies. Furthermore, an upregulated membrane Hsp70 density could be detected on relapse tumors and metastases compared to primary tumors. In multiple studies, the malignancy of tumors correlates positively with the Hsp70 expression density in the cytoplasm and on the plasma membrane $[8,11]$.

For a specific in vivo tumor targeting which is mediated by membrane-bound Hsp70, we developed the membrane Hsp70-specific antibody cmHsp70.1 [9,15]. To utilize the beneficial features of targeting membrane Hsp70 with the imaging capabilities of gold as a contrast agent, we developed an AuNP formulation, functionalized with cmHsp70.1 monoclonal antibody to target membrane-bound Hsp70 on tumor cells in vitro and in vivo. In previous studies, we could demonstrate a rapid and specific binding, uptake, and internalization of cmHsp70.1-AuNPs into tumor cells in vitro, leading to a high intracellular accumulation. Furthermore, following incubation of viable tumor cells with cmHsp70.1-AuNPs, no severe toxic side effects were observed up to a concentration of $10 \mu \mathrm{g} / \mathrm{mL}$ [16]. 


\section{Results}

\subsection{Functionalization of AuNPs with cmHsp70.1 Antibody}

For the coupling of mouse IgG1 isotype-matched or cmHsp70.1 antibody to AuNPs, we used a standard maleimide coupling reaction (Figure 1A). The size of the mean hydrodynamic diameter of unconjugated AuNPs was determined to be $45 \pm 14 \mathrm{~nm}$ (Figure 1B, top panel). The sizes of cmHsp70.1 antibody-conjugated cmHsp70-AuNPs were $54 \pm 11 \mathrm{~nm}$ (Figure 1B, middle panel) and $59 \pm 18 \mathrm{~nm}$ for IgG1 isotype-matched control antibody-conjugated gold nanoparticles (IgG1-AuNPs) (Figure 1B, bottom panel). No self-aggregation was observed in aliquotes of the conjugated as well as the unconjugated AuNPs in phosphate buffered saline (PBS) at $37^{\circ} \mathrm{C}$ during $24 \mathrm{~h}$. After 4 weeks of storage at $4{ }^{\circ} \mathrm{C}$, self-aggregation of the particles was observed. An exemplary size distribution histogram is given in Figure A1. To determine the Hsp70-specific binding capacity of cmHsp70.1-AuNPs, we performed analysis of the interaction of cmHsp70.1-AuNPs as well as IgG-AuNPs with recombinant human Hsp70, using an agglomeration assay, as described by Shevtsov et al. [17]. Following a $4 \mathrm{~h}$ incubation period with recombinant Hsp70, the size of the formed clusters, as determined by dynamic light scattering (DLS), was larger after incubation with cmHsp70.1-AuNPs (mean event sizes: $152 \mathrm{~nm}$ and $2420 \mathrm{~nm}$ ) than with IgG1-AuNPs $(52.9 \mathrm{~nm})$, indicating the formation of ligand-mediated agglumerates. The hydrodynamic diameter of recombinant Hsp70 was determined to be $9.7 \mathrm{~nm}$ (Figure A2).
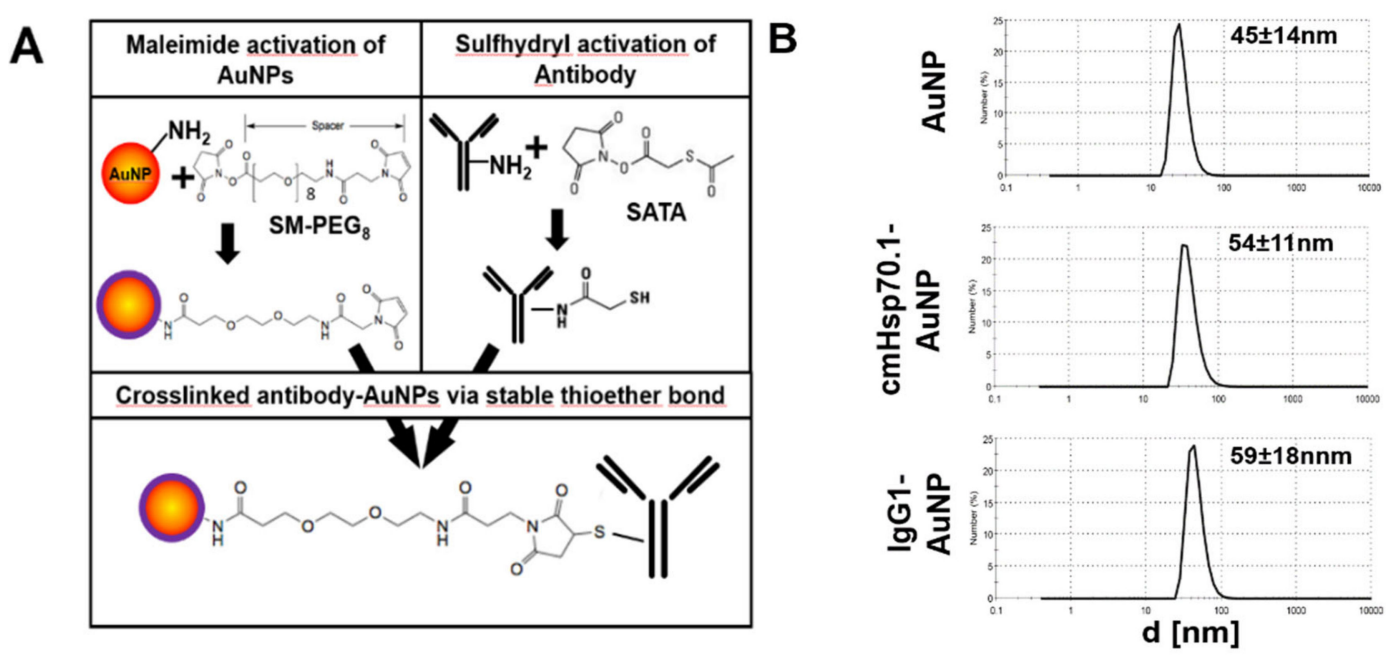

Figure 1. Antibody conjugation of gold nanoparticles (AuNPs) and characterization: (A) Coupling reaction of maleimide-activated AuNPs and sulfhydryl-activated monoclonal antibodies. (B) Size distribution of the differently functionalized AuNPs, given in size by number histograms.

\subsection{Uptake and Internalization of Functionalized AuNPs in Tumor Cells In Vitro}

To verify the binding capacities and specific uptake of cmHsp70.1-AuNPs in comparison to control nanoparticles (AuNPs and IgG1-AuNPs) in vitro, we performed binding tests on viable, membrane Hsp70-positive tumor cells. To determine the density of the target antigen, the cell lines 4T1 and CT26 were analyzed for their membrane and cytosolic expression of Hsp70. The Hsp70 high expressing cell line $4 \mathrm{~T} 1$ showed a membrane Hsp70-positive phenotype on $67 \% \pm 9 \%$ of the cells, whereas CT26 cells showed a positive phenotype on $43 \% \pm 6 \%$ of the cells (Figure $2 \mathrm{~A}$ ). For determination of the total Hsp70 density in the cell lines, an in-cell ELISA technique was established for cells grown in chamber slides. The Hsp70 mean signal intensity in 4T1 and CT26 cell lines were $150.11 \times 10^{3} \pm 24.92 \times 10^{3}$ a.u. and $89.39 \times 10^{3} \pm 17.19 \times 10^{3}$ a.u., respectively (Figure $2 \mathrm{~B}$ ). These data were verified by a sandwich ELISA of cell lysates derived from $10 \times 10^{6}$ cells of each cell line, resulting in Hsp70 contents of $4.28 \pm 1.74 \mathrm{ng} / \mathrm{mL}$ and $1.17 \pm 0.72 \mathrm{ng} / \mathrm{mL}$ for $4 \mathrm{~T} 1$ and CT26 cells, respectively (Figure $2 \mathrm{C}$ ). Subsequently, both cell lines were incubated with the three different types of AuNPs for $24 \mathrm{~h}$ at $37^{\circ} \mathrm{C}$ to mimic 
the uptake in living cells. In both cell lines, the content of AuNPs was visualized by brightfield and electron microscopy (Figure 3). Compared to blank AuNPs (Figure 3A, left panel) and IgG1-AuNPs (Figure 3A, middle panel), which showed minor cytosolic uptake, cmHsp70.1-AuNPs displayed the strongest accumulation in both 4T1 and CT26 cells (Figure 3A, right panel). In transmission electron microscopy (TEM), the cmHsp70.1-AuNPs have been found to accumulate in intracellular vesicles of both $4 \mathrm{~T} 1$ and CT26 cells $24 \mathrm{~h}$ after incubation. A representative image of cmHsp70.1-AuNPs in 4T1 cells is shown in Figure 3B.

A
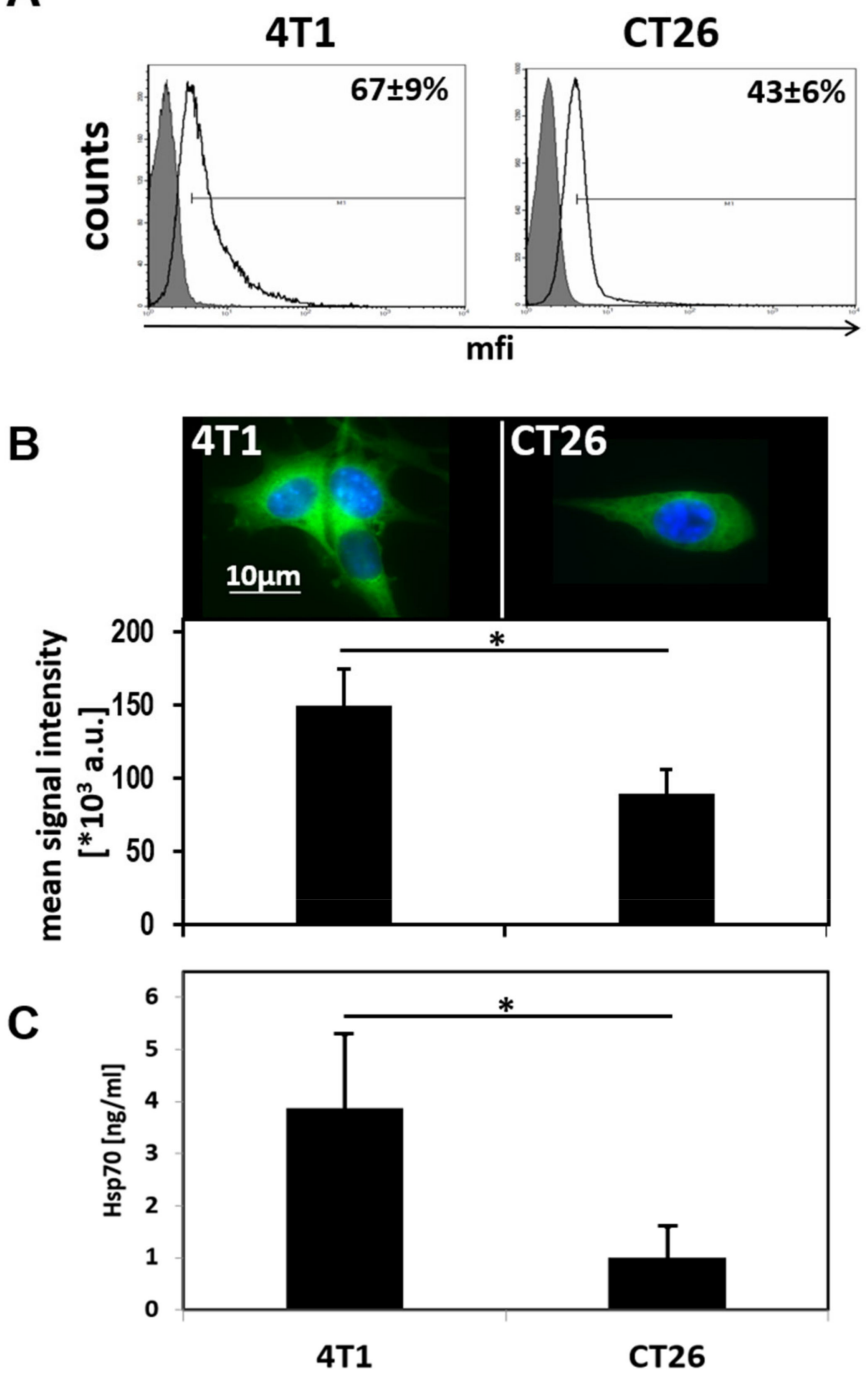

Figure 2. Quantification of Hsp70 in target tumor cell lines: (A) Plasma-membrane bound Hsp70 on 4T1 (left) and CT26 (right) cell lines, as determined by flow cytometry. (B) Quantitative staining of total Hsp70 in 4T1 and CT26 cells (upper panel) and quantification (lower panel), as determined by an in-cell ELISA technique. (C) Quantification of total Hsp70 in whole cell lysates of 4T1 and CT26 cell lines, as determined by an Hsp70 sandwich ELISA. ${ }^{*} p<0.05$. 

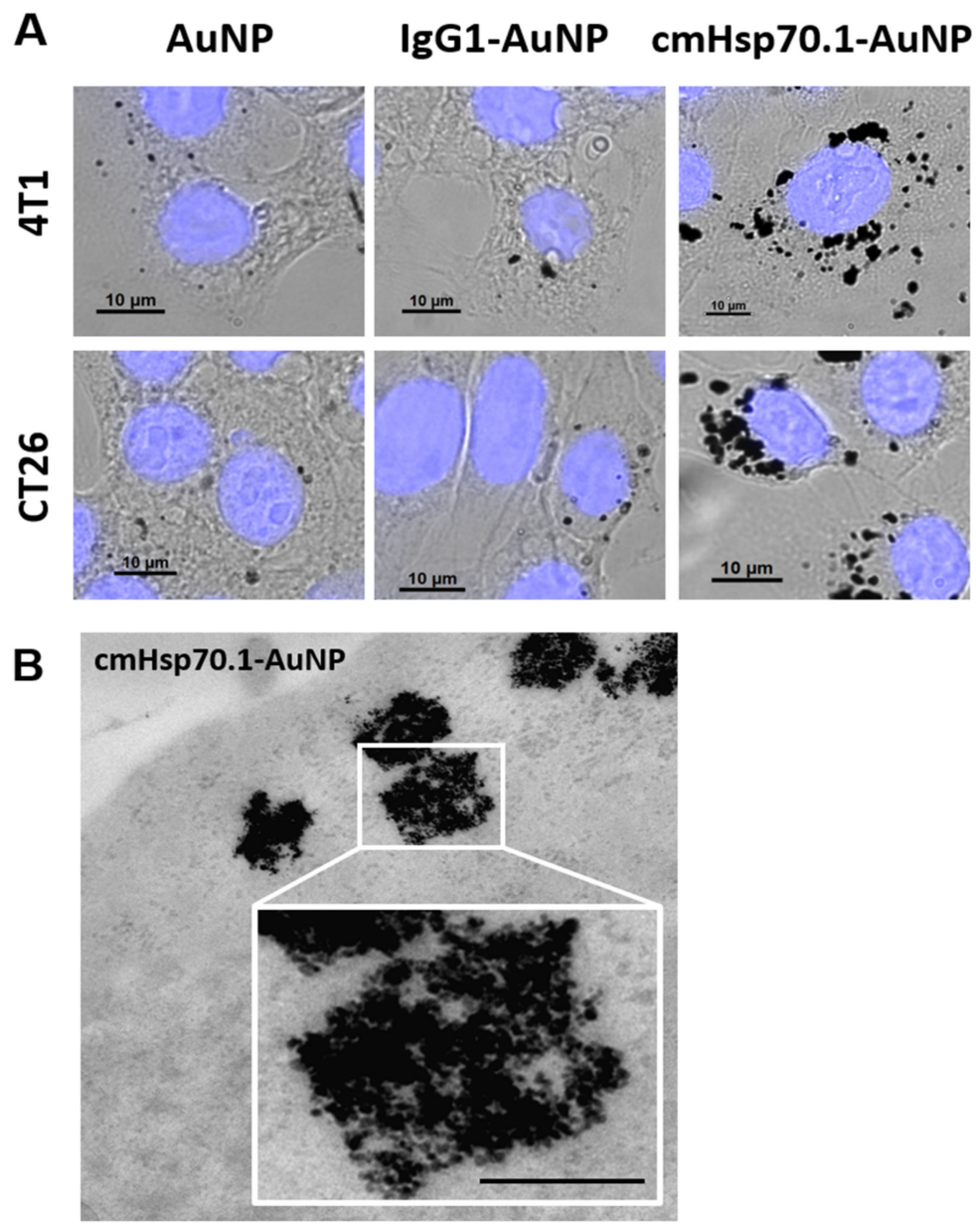

Figure 3. Uptake of AuNPs in tumor cells: (A) Intracellular accumulation of blank AuNPs (left), IgG1-AuNPs (middle), and cmHsp70.1-AuNPs (right) in 4T1 (upper panel) and CT26 (lower panel) cells. (B) TEM image of intracellular accumulations in 4T1 cells. Magnification is of the indicated area (white box). Scale bar, $1 \mu \mathrm{m}$.

\subsection{Accumulation of Functionalized AuNPs in Tumors In Vivo}

To investigate the specificity and sensitivity of cmHsp70.1-conjugated AuNPs to target tumors in vivo, syngeneic tumor models in Balb/c mice were established. Animals were injected orthotopically (o.t.) with $4 \mathrm{~T} 1$ and subcutaneously with CT26 tumor cells, respectively. When tumors reached a size of $200 \mathrm{~mm}^{3}$, two times $2.5 \mathrm{mg}$ of AuNPs of each group (AuNP, IgG1-AuNP, and cmHsp70.1-AuNP) were injected i.v. consecutively at an interval of $24 \mathrm{~h}$ (Figure 4).

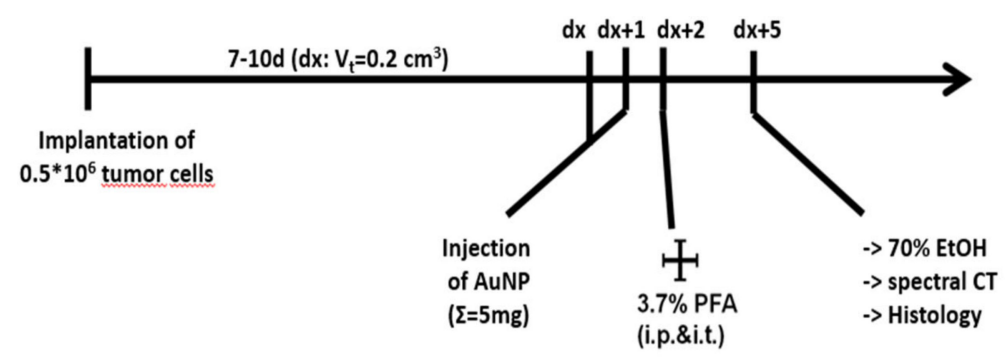

Figure 4. Timeline of the in vivo experiments. 
Twenty-four hours after the second injection, mice were euthanized and fixed and subsequently imaged using spectral-CT or tumors and organs were directly applied to histological analysis. In parallel, single cell suspensions of tumors of both models have been analyzed for their plasma membrane Hsp70 status. To characterize the tumor models regarding the main features which determine the accumulation of molecular functionalized contrast agents in vivo, tumors were histologically analyzed for the target antigen content (Hsp70) in the cytosol as well as on the plasma membrane. Their vascularization status (CD31) and the presence of tumor infiltrating macrophages (F4/80) have been investigated as well. Both tumor types, 4T1 (o.t.) and CT26 (s.c.), displayed similar vascularization and infiltration of macrophages, indicating comparable effects on the NP input through these routes. Immunohistological Hsp70 staining revealed a strong expression in both tumor models, featuring cytosolic as well as nuclear Hsp70 expression. However, 4T1 tumors showed a more patterned architecture of the Hsp70 density. To investigate the membrane Hsp70 status of the tumors in vivo, a single cell suspension of freshly dissected tumors was investigated. With 76\% $\pm 7 \%$ and $67 \% \pm 13 \%$ membrane Hsp 70 -positive viable tumor cells, 4T1 and CT26 tumors grown in vivo, respectively, showed a slightly higher Hsp70 expression density compared to the in vitro cultured cells. However, the increased width of the cytometric data, as given in histograms, indicates an increased heterogeneity in the membrane Hsp70 expression pattern in in vivo grown tumors (Figure 5).
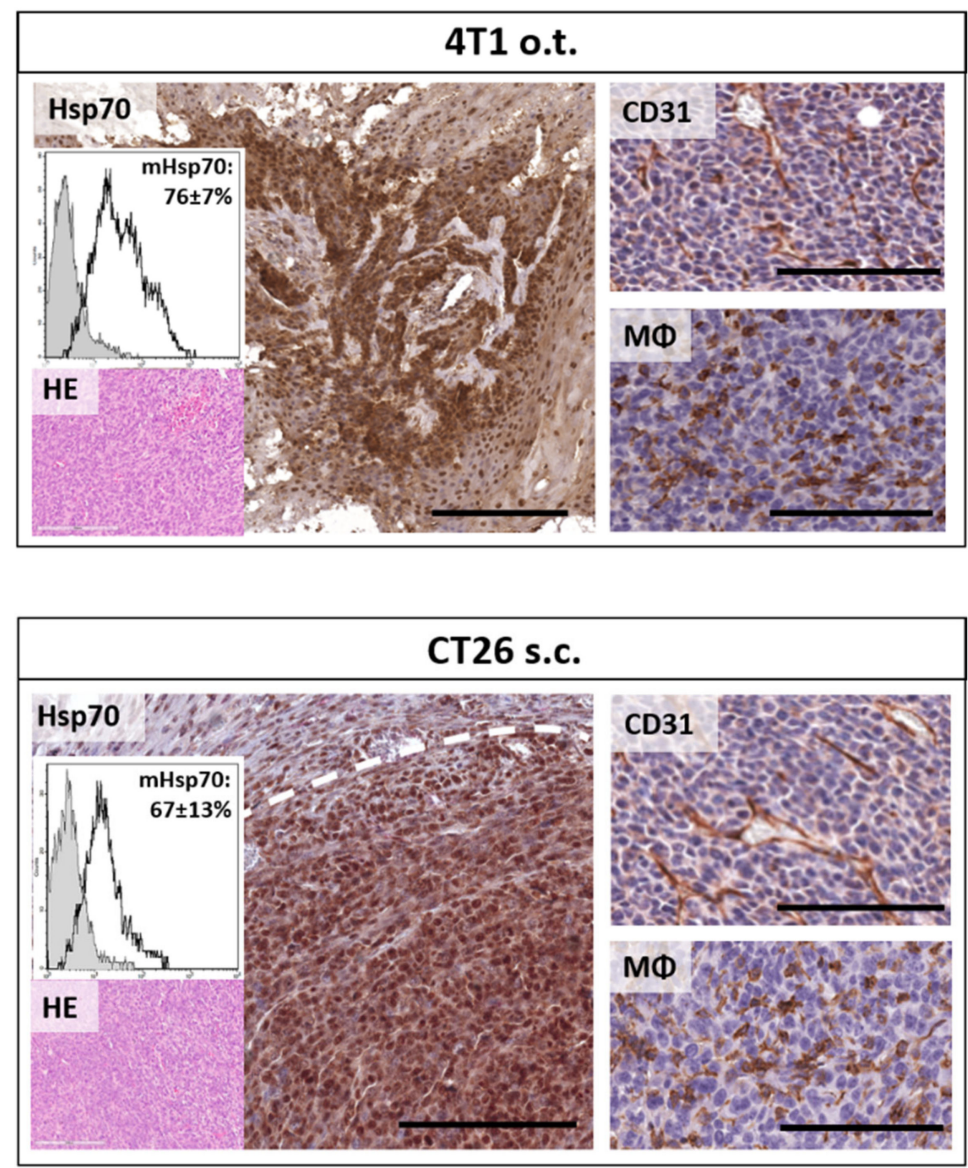

Figure 5. Tumor characterization: Orthotopic (o.t.) 4T1 (upper panel) and subcutaneous (s.c.) CT26 (lower panel) tumors were analyzed with regard to membrane (flow cytometry analysis, upper inlay) and overall (immunohistochemistry, IHC) Hsp70 expression as well as their content of CD31 positive vessels (IHC and CD31) and the infiltration of macrophages (MФ, IHC, and F4/80). Hematoxylin \& Eosin (H\&E) was used as an overview stain (lower inlay). Scale bars, $200 \mu \mathrm{m}$ (Hsp70) and $100 \mu \mathrm{m}$ (CD31 and MФ). 
In a next step, we investigated the feasibility of cmHsp70.1-AuNPs as a contrast agent in a first cohort of tumor-bearing mice. For this pilot study, three mice with subcutaneous CT26 tumors underwent spectral CT imaging postmortem. Each mouse had received one type of AuNP $24 \mathrm{~h}$ before sacrifice. Interestingly, in all animals, we were able to detect AuNPs in the tumors with the highest density of nanoparticles in the tumor periphery. Nevertheless, we also noticed some striking differences. The mouse which was treated with IgG1-AuNPs presented the lowest content of AuNPs inside the tumor $\left(3.3 \mu \mathrm{g} \mathrm{Au} / \mathrm{mm}^{3}\right.$ tumor) with a very low accumulation of particles within the tumor center (Figure 6C,D). In the mouse which was treated with unconjugated AuNPs, $4.3 \mu \mathrm{g}$ Au/ $/ \mathrm{mm}^{3}$ was detected in total but mainly at the periphery of the tumor, with considerably less AuNPs in the tumor center (Figure 6A,B). In case of an injection of cmHsp70.1-AuNPs, $4.4 \mu \mathrm{g} \mathrm{Au} / \mathrm{mm}^{3}$ was found inside the tumor. Despite similar amounts of different AuNPs in the tumor area, the distribution pattern of the AuNP formulation differed drastically. CmHsp70.1-AuNPs were found to be located in the tumor periphery and highly dispersed in the tumor center (Figure 6E,F).
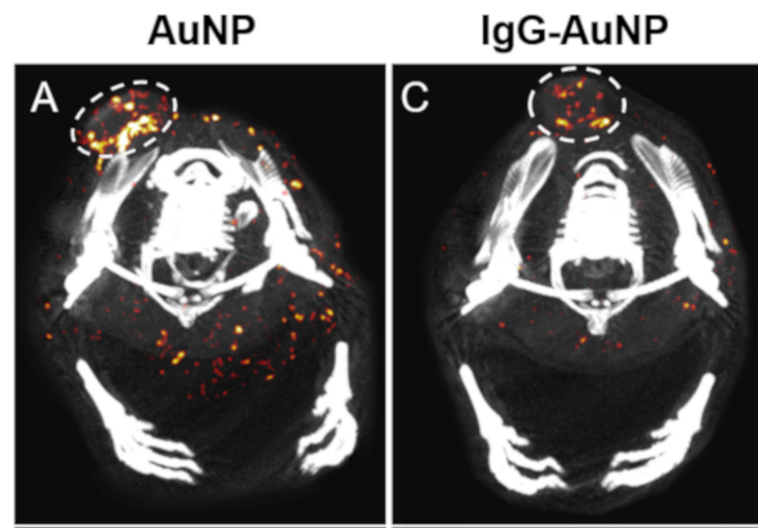

cmHsp70.1-AuNP
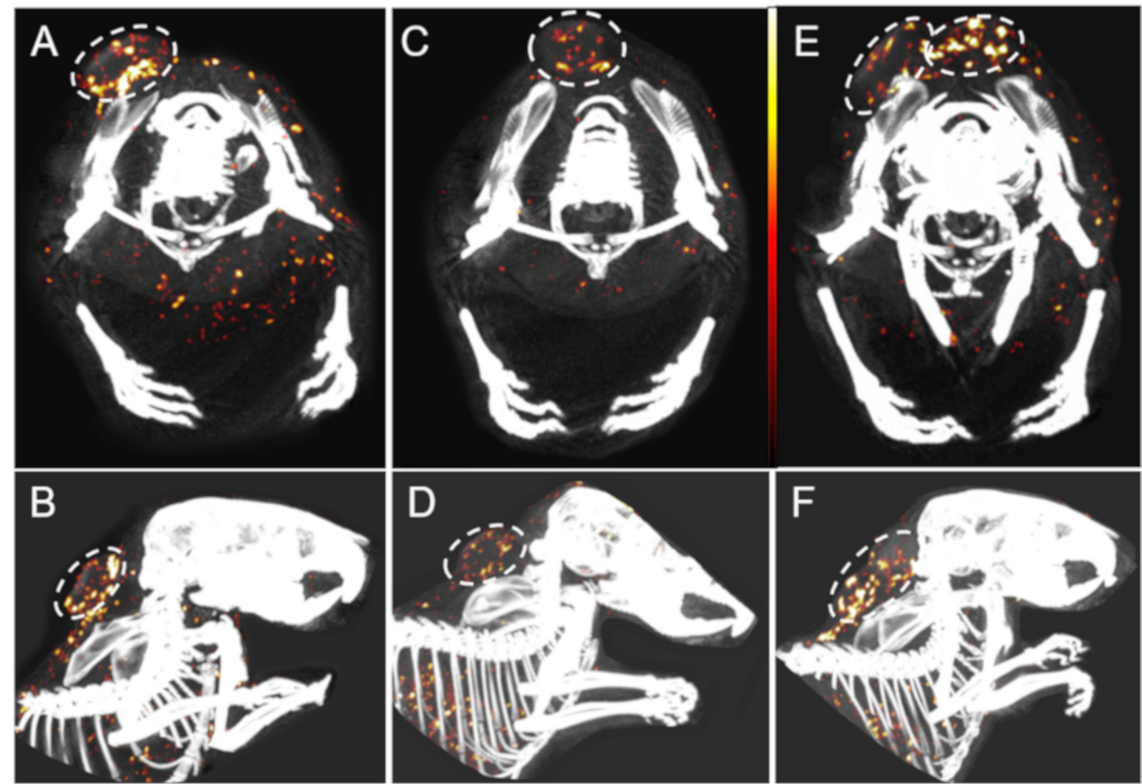

Figure 6. Tumor detection using spectral-CT. Upper Row (A,C,E): axial view, bottom row (B,D,F): sagital view. AuNP amounts are pseudo-coloured from black $(6.5 \mathrm{mg} / \mathrm{mL})$ over red $(10 \mathrm{mg} / \mathrm{mL})$ to white $(13.5 \mathrm{mg} / \mathrm{mL})$. (A,B) spectral CT-views of mice injected with AuNPs; (C,D) spectral CT-views of mice injected with IgG-AuNPs; (E,F) spectral CT-views of mice injected with cmHsp70.1-AuNPs.

The spectral CT-based biodistribution analysis detected a high accumulation of AuNPs in the spleen, lower amounts in the liver, and very low amounts of AuNPs in the lung. The other organs did not exhibit concentrations which were high enough to generate a signal in the spectral CT measurements. However, to prove data for statistical significance, the number of mice within the study groups have to be increased to relevant numbers in future experiments. The tumors were further analyzed for their gold content by histology (Figure 7). 


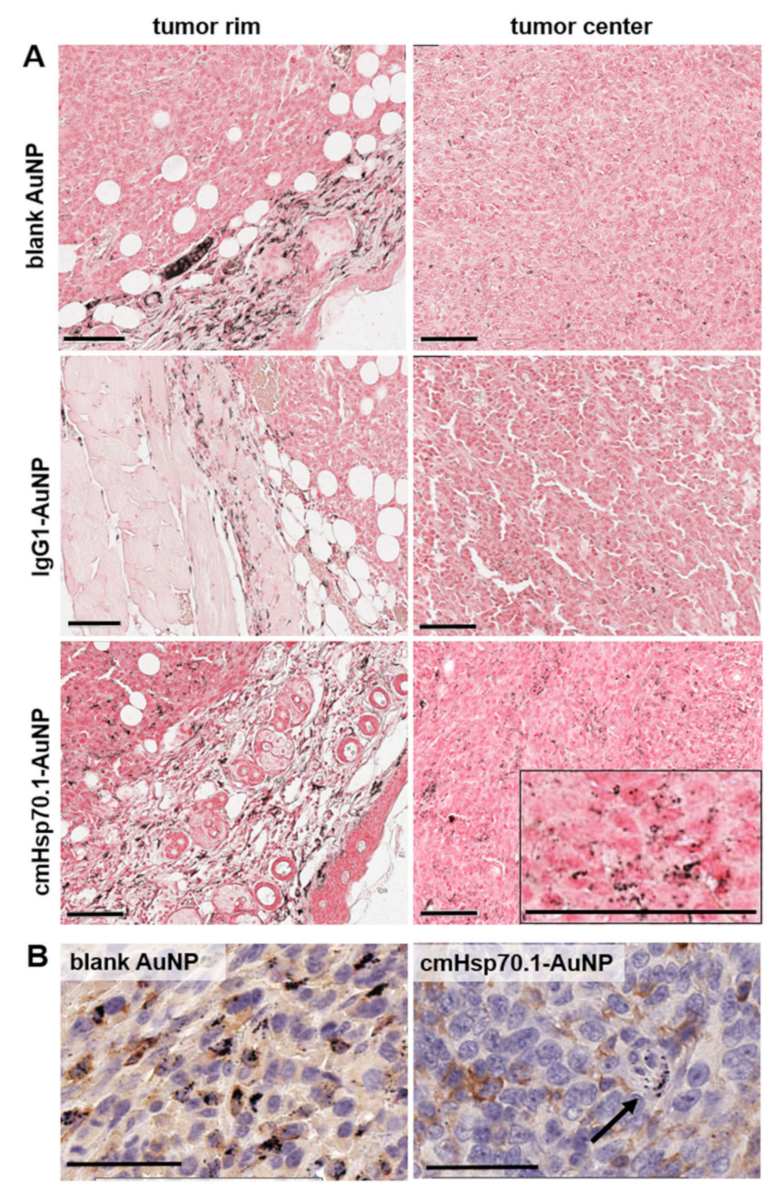

Figure 7. AuNP uptake and distribution in CT26 tumors: (A) Silver enhancement of AuNPs. Upper row: blank AuNPs, middle row: IgG1-AuNPs, bottom row: cmHsp70.1-AuNPs. Left: Region of Interest (ROI) at tumor rim area, right: ROI set to tumor center. Scale bars, $100 \mu \mathrm{m}$. (B) Double staining of Macrophages (F4/80, brown) and silver enhancement of AuNPs (black). Arrow: single-positive cells for AuNPs. Scale bars: $5 \mu \mathrm{m}$.

Sections were treated with silver enhancement to visualize AuNPs by light microscopy (Figure 7A). As revealed by spectral-CT, histological analysis confirmed the varying intratumoral distribution of the three groups of AuNPs. In tumors of mice which were treated with cmHsp70.1-AuNPs, a rather homologous distribution of NPs was observed throughout the whole tumor volume compared to the blank AuNPs or IgG1-AuNPs. Notably, the enrichment of AuNPs at the tumor rim following i.v. injection of blank AuNPs was most likely due to F4/80 positive monocyte/macrophage lineages with internalized AuNPs (Figure 7B, left). In contrast, next to the payload introduction via macrophages, cmHsp70.1-AuNPs were also found in large amounts in F4/80-negative tumor cells. Consequently, an extended accumulation of the cmHsp70.1-AuNPs was also detected in the tumor center. In this region, we also identfied less AuNP containing macrophages (Figure 7B, right). IgG1-AuNPs showed the lowest accumulation in all regions of the tumor (Figure 7A, middle). These NPs, besides their lack of targeting ability, exhibited equal biocompatibility to that of cmHsp70.1-AuNPs due to the conjugation of the murine IgG1 antibody. Consequently, these IgG1NPs resulted in the lowest intratumoral accumulation yield.

To obtain the in vivo biodistribution characteristics of cmHsp70.1-AuNPs, $24 \mathrm{~h}$ following systemic application, we further analyzed silver enhanced sections of tumors, liver, spleen, kidneys, heart, lungs, and intestines of another group of tumor-bearing Balb/c mice (after subcutaneous and orthotopic injection) (Figure 8). 

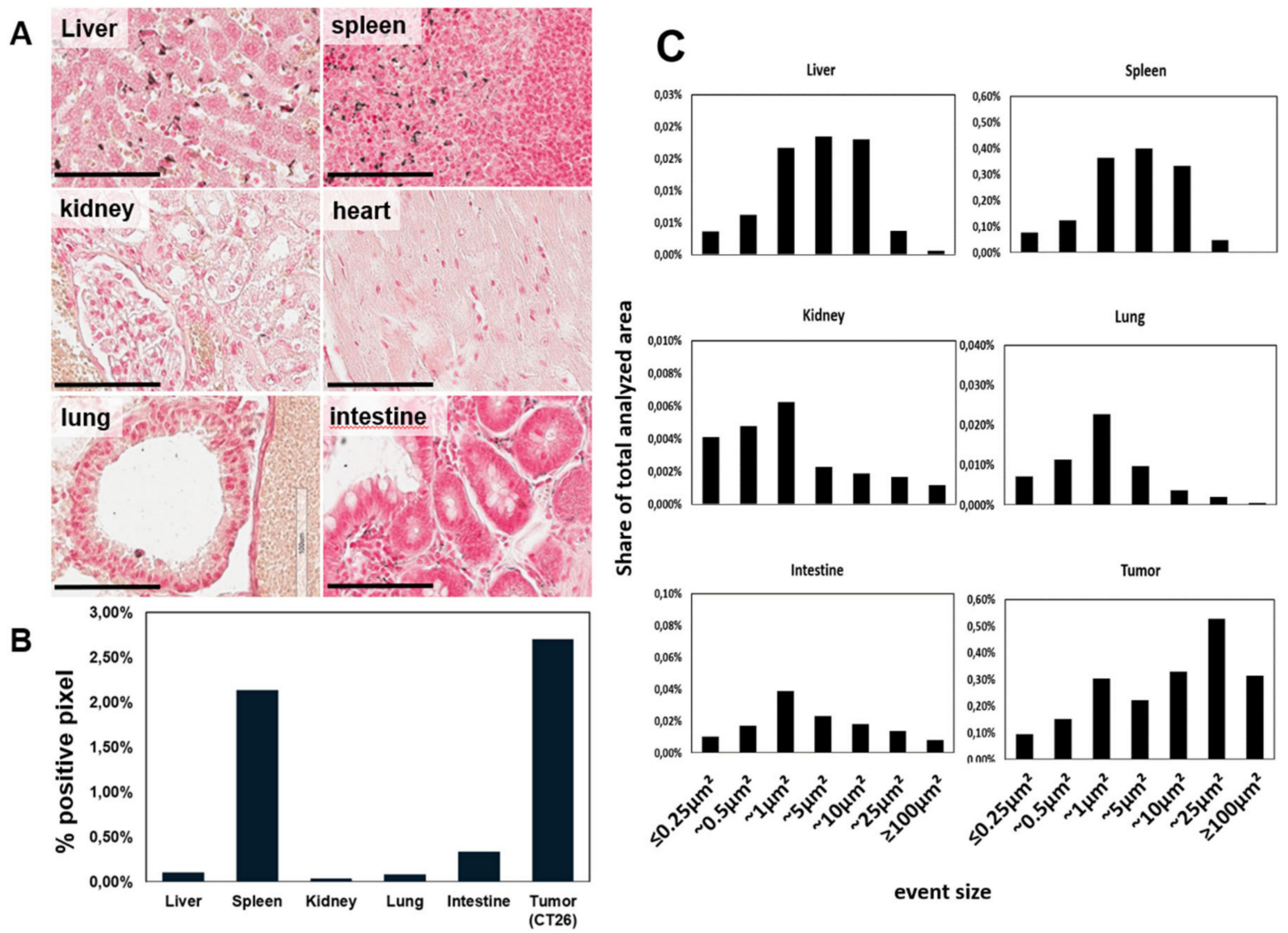

Figure 8. Biodistribution of cmHsp70.1-AuNPs: (A) Silver enhancement staining of liver, spleen, kidney, heart, lung, and intestine. Scale bar, $100 \mu \mathrm{m}$. (B) Pixel analysis of silver enhancement stainings in tumors and organs, given in positive pixel $/ \mathrm{mm}^{2}$ tissue. (C) size distribution of silver enhanced cmHsp70.1-AuNP signals in different organs following i.v. injection.

For an improved accuracy of the analysis, we used a machine-learning approach. The algorithm for the analysis of sections was trained on 28 slides in total and was applied for the analysis of 14 slides. In comparison to the organs, the highest accumulation of cmHsp70.1-AuNPs was found in the tumors, with $85.98 \times 10^{3} \pm 4.94 \times 10^{3}$ positive pixel per $\mathrm{mm}^{2}$, which equals to $2.7 \%$ positive pixels per section (Figure $8 \mathrm{~B}$ ). Using the machine-learning approach, we found the majority of the nanoparticles accumulated in spleen $\left(14.04 \times 10^{3} \pm 1.37 \times 10^{3} \mathrm{pixel} / \mathrm{mm}^{2}\right)(2.13 \%$ signal $/$ section $)$, liver $\left(13.34 \times 10^{3} \pm 0.7 \times 10^{3} \mathrm{pixel} / \mathrm{mm}^{2}\right)$ $(0.11 \%$ signal/section $)$, and intestine $\left(9.48 \times 10^{3} \pm 1.37 \times 10^{3} \mathrm{pixel} / \mathrm{mm}^{2}\right)(0.34 \%$ signal $/$ section $)$, followed by lungs $\left(6.28 \times 10^{3} \pm 1.30 \times 10^{3} \mathrm{pixel} / \mathrm{mm}^{2}\right)(0.09 \%$ signal/section $)$. In muscle, as represented by heart tissue, the accumulation of AuNPs was below the detection limit. Kidney was rarely affected, indicating an enterohepatic secretion of the AuNPs. In addition to the analysis of the overall entry of AuNPs in the organs and tumors, we utilized the machine-learning approach to analyze the size distribution of the nanoparticle agglumerations within the organs. The majority of positively stained events in liver and spleen resulted in a size range up to $10 \mu \mathrm{m}$. Accumulation of events in this size range might be suggested to be due to incorporation of the AuNP by macrophages and Kupffer cells, as indicated also in Figure 7B. The majority of AuNPs in kidney, lung, and intestine yielded in agglumerates of about $1 \mu \mathrm{m}$ in size. In the tumor, cmHsp70.1-AuNP spots of $25 \mu \mathrm{m}^{2}$ were dominant, followed by spots of $1 \mu \mathrm{m}^{2}$ (Figure 8C). As tumor-associated macrophages exhibit large cytoplasmatic volumes, the accumulation of AuNPs above $10 \mu \mathrm{m}^{2}$ suggest the appearance of this cell type. However, aggregates of $1 \mu \mathrm{m}^{2}$ point to tumor cells with smaller cytoplasmic space as tumor cells. This finding is also supported by microscopical analysis of in vitro grown tumor cells with the majority of NP accumulating in cellular organelles of about $1 \mu \mathrm{m}$, following endocytosis (Figure 3). 


\section{Discussion}

The discovery of suitable contrast agents for the visualization of tumors is one of the most important areas in clinical oncology. In tumor imaging, CT imaging is the most commonly used technique featuring fast scanning speed with high spatial resolution of a large portion of the body. Functional molecular imaging can be accomplished with positron-electron-tomography (PET), often used in combination with CT. However, certain limitations affect the quality of tumor visualization. PET imaging using ${ }^{18} \mathrm{~F}$-FDG is highly dependent on a high tumor cell metabolism compared to the surrounding normal tissue. Furthermore, PET tracers need to exert ionizing effects, which in turn increases the patient's risk to accumulate DNA mutations. An approach to overcome the limiting effects of PET/CT led to the development of spectral-CT analyzers [6,18], which use the k-edge discrimination of elements, allowing for their specific identification inside the body [19]. Another advantage of the spectral segmentation is the possibility to utilize multiple contrast agents within one imaging session, which reduces the X-ray expositions of the patient.

One further limitation of PET imaging is the spatial detection limit, leading to a potential miss of small lesions. Therefore, the usage of tumor-specific markers is beneficial.

Herein, the major stress-inducible member of the HSP70 family, Hsp70 (HspA1A), was used as a target for the tumor-specific uptake of functionalized AuNPs in different tumor entities. Hsp70 is expressed on the plasma membrane of a variety of tumor entities, whereas normal cells lack an Hsp70 membrane expression [9]. However, further studies investigate the role of membrane-associated Hsp70 in the context of inflammatory diseases, such as sepsis. It was found that membrane Hsp70 also plays a role in the regulation of inflammatory responses. A study of Hirsch et al. described polymorphonuclear neutrophils (PMNs), expressing mHsp70. These PMNs are recognized and lysed by $\gamma \delta$ T-lymphocytes and therefore protect the host cells from inflammation-induced damage [20].

In previous studies, we observed that tumor cell membrane-associated Hsp70 is rapidly internalized and therefore mediates an efficient uptake of Hsp70-binding probes into the cytoplasm, such as fluorescence-labeled cmHsp70.1 antibody [15] and tumor-penetrating peptide (TPP) [21,22]. Since the binding epitope of cmHsp70.1 antibody is identical in mouse and human tumor cells [9], murine CT26 colon and mammary 4T1 tumor cell lines were used in the present study.

The application of AuNPs for imaging in vivo is a promising new approach in the field of in vivo imaging $[7,23,24]$. The uptake of antibody-conjugated nanoparticles into tumor cells is dependent on several factors: the expression density of receptors, which are expressed on the target cells; the distribution of the target epitopes throughout the cells [25]; the affinity of the tracer to the membrane epitope; and the speed of internalization $[21,26]$.

In order to monitor the efficiency of functionalized AuNPs in vitro and in vivo, we applied different imaging modalities. Dynamic light scattering is a widely used technique to determine the hydrodynamic diameter of AuNPs in the nm- $\mu \mathrm{m}$ range.

Furthermore, the quantification of AuNPs within tumor cells is of relevance to estimate the concentration of nanoparticles that is necessary for noninvasive in vivo imaging of tumors as well as for their use as therapeutic agent. In our in vivo/ex vivo setup, we were able to detect aggregates of AuNPs in tumors and organs in perinuclear areas of around 1-2 $\mu \mathrm{m}$ in diameter as well as larger aggregates of around $25 \mu \mathrm{m}$ in diameter. The presented machine-learning approach has proven to be beneficial for the analysis of the distribution of AuNPs. Next to calculating the quantity of gold signal within tumors and organs, we were able to separate the signal into groups, which allows for an easy analysis of AuNPs within different cell types. This is important for a more precise prediction of the biodistribution and possible toxic side effects of AuNPs.

Toxic side effects of AuNPs following i.v. application were investigated in previous studies [27,28]. No negative side effects such as loss in body weight or organic dysfunctions were observed in these experiments up to a concentration of $500 \mu \mathrm{g} / \mathrm{mL}$ [29]. Concordantly, in the in vivo experiments of this study, we did not observe any sign of toxicity at the injected concentration of $5 \mathrm{mg}$ AuNPs per mouse. However, additional pharmacological and toxicological studies are needed to prove safety. 
On the basis of the specific and quantitative uptake of cmHsp70.1-AuNPs in Hsp70-positive tumor cells and its imaging properties, our approach hints at a possible beneficial use in radiation therapy. Numerous studies have reported on the radiation-enhancing effect of AuNPs within tumor tissue $[30,31]$.

First, promising findings for radiotherapy enhancement of AuNPs were achieved in preclinical mammary carcinoma studies [32]. The results of Hainfeld et al. showed an $86 \%$ 1-year survival for a combinatorial therapy of irradiation in presence of NPs compared to $20 \%$ for radiotherapy alone. Probable mechanisms involved in radiosensitization are, besides changes in the cell cycle or an elevated reactive oxygen species, the production and the release of secondary Auger electrons by gold in very close proximity to the nucleus [31]. In previous in vitro studies on the intracellular distribution of Hsp70 targeting AuNPs, we observed an increased accumulation of the NPs in close proximity to the nucleus 24 to $48 \mathrm{~h}$ after incubation [16], indicating possible beneficial effects of this approach for radiotherapeutical interventions. In summary, we demonstrate that the functionalization of AuNPs with cmHsp70.1 antibody is a highly promising approach for in vivo tumor targeting. Our preclinical studies show that the accumulation of AuNPs within the investigated tumors was sufficient for visualization by spectral-CT which allows 3D reconstructions and quantifications.

\section{Materials and Methods}

\subsection{Antibody Coupling of AuNPs}

Coupling of Hsp70-specific antibody (cmHsp70.1, multimmune, Germany) or an isotype-matched control IgG1 antibody (Sigma Aldrich, St. Luis, Mo, USA) to AuNPs (Nanopartz, Loveland, CO, USA) was done as described before [16]. Briefly, polyethylenglycol (PEG)-amine-coated spherical gold nanoparticles of $30 \mathrm{~nm}$ diameter were maleimide activated (Pierce, Thermo Fischer Scientific, Rockford, IL, USA) and incubated over night with sulfhydryl-activated antibodies. Antibody-coupled AuNPs or unconjugated AuNPs were analyzed and used for experiments within $24 \mathrm{~h}$. Nanoparticles were analyzed (size, aggregation) by dynamic light scattering (DLS, Zetasizer NanoS, Malvern Instruments, Malvern, UK). Measurements were done in triplets and mean values were calculated.

\subsection{Characterization of AuNPs}

Antibody-conjugated AuNPs or unconjugated AuNPs were used for experiments directly after coupling. For AuNP characterization and controlling their aggregation, particle size was analyzed by dynamic light scattering (Zetasizer NanoS; Malvern Instruments, Malvern, UK). Only nanoparticles that produced single peaks were used for experiments. For analysis of the specific interaction of differentially functionalized AuNPs with Hsp70, $150 \mu \mathrm{g} / \mathrm{mL}$ nanoparticles dissolved in PBS were incubated with recombinant Hsp70 protein at a concentration of $0.5 \mu \mathrm{g} / \mathrm{mL}$. Following a 4-h incubation time, the size of the clusters formed by IgG1-AuNP + Hsp70 and cmHsp70.1-AuNP + Hsp70, respectively, was analyzed by DLS.

\subsection{Cell Culture}

Murine colon carcinoma cell line CT26 (CT26.WT; American type culture collection (ATCC) \#CRL-2638) and the mouse mammary carcinoma cell line 4T1 (ATCC \#CRL-2539) were cultured in Roswell Park Memorial Institute 1640 medium supplemented with 10\% (v/v) heat-inactivated fetal calf serum, $2 \mathrm{mM} \mathrm{L-glutamine,} 1 \mathrm{mM}$ sodium pyruvate, and antibiotics $(100 \mathrm{IU} / \mathrm{mL}$ penicillin and $100 \mu \mathrm{g} / \mathrm{mL}$ streptomycin). Cells were incubated at $37{ }^{\circ} \mathrm{C}$ in $95 \%$ humidity and $5 \%(\mathrm{v} / \mathrm{v}) \mathrm{CO}_{2}$ and cultivated twice a week.

\subsection{Assessment of Hsp70 Content of the Tumor Cells}

The Hsp70 membrane phenotype of the cells was assessed by flow cytometry. Single cell suspensions of tumor cell lines were incubated with fluorescein-isothiocyanate (FITC)-conjugated 
cmHsp70.1 mAb for $30 \mathrm{~min}$ on ice. As controls, conjugation of an IgG1 isotype-matched antibody was done. After washing and adding propidium-iodide (PI) for life and dead discrimination, binding of antibodies was measured using a FACSCalibur instrument (BD Biosciences, Heidelberg, Germany). Data were analyzed using CellQuest Pro 6.0 software. Only PI-negative, viable cells were analyzed. To determine the membrane Hsp70 status of tumors grown in vivo, single cell suspension of freshly dissected tumors was generated by combined chopping and trypsin treatment of the tumors. Here, anti-mouse CD45 APC antibody was added to cmHsp70.1-FITC to distinguish tumor cells from mononuclear blood cells and infiltrated macrophages.

In-cell ELISA was performed, as described previously [21]. Briefly, cells grown in chamber slides were fixed with DAKO Fix \& Perm kit (DAKO, Jena, Germany) and cellular membranes were permeabilized and incubated with cmHsp70.1-FITC antibody. Following microscopy with comparable settings, quantification of fluorescence signal was determined on the mean signal intensity values by Image J 1.52a image analysis software.

Quantification of the Hsp70 content was confirmed by an Hsp70 sandwich ELISA, as described elsewhere [33]. Shortly, after determination of the cell count, cells were lysed by incubation in Tris-HCl-based buffer containing 1\% Triton-X100 and SDS. After centrifugation, the Hsp70 concentration in the supernatant was measured by total Hsp70 ELISA kit (R\&D systems, Minneapolis, MN, USA) as described by the manufacturer. Each supernatant sample was measured in duplicates.

\subsection{Animals}

All animal procedures and their care were conducted in conformity with national and international guidelines (EU 2010/63) with approval from the local authorities of the Government of Upper Bavaria and ethical committee of Pavlov First Saint Petersburg State Medical University (St. Petersburg, Russia) (2015/068) and supervised by respective animal care and use committees. Animals were housed in standard animal rooms in individually ventilated cage systems (IVS Techniplast, Buggugiate, Italy) under specific pathogen-free conditions with free access to water and standard laboratory chow ad libitum. In total, 6 female Balb/c mice (aged 10-14 weeks, Charles River Laboratories, Sulzfeld, Germany) were used. Induction of subcutaneous tumors was done under inhalation anesthesia $\left(1.8 \%\right.$ isoflurane with medical $\left.\mathrm{O}_{2}\right)$ by injection of $5 \times 10^{5} \mathrm{CT} 26$ cells subcutaneously in the neck area or of $5 \times 10^{5} 4 \mathrm{~T} 1$ cells orthotopically in the 4 th mammary fat pad. When tumors reached a size of $200 \mathrm{~mm}^{3}$, AuNPs were intravenously injected using standard procedures. In total, $5 \mathrm{mg}$ unconjugated, IgG1-, or cmHsp70.1-AuNPs, suspended in phosphate buffered saline, were injected in a consecutive pattern of two times $2.5 \mathrm{mg}$ per day within $48 \mathrm{~h}$. Another $24 \mathrm{~h}$ after the second application, mice were euthanized under deep anesthesia, fixed in $4 \%$ neutral-buffered formalin for 5 days, and stored in $70 \%$ ethanol for further analysis.

\subsection{Bright Field Microscopy}

For light microscopy, cells were grown in 8-well chamber slides (NUNC-Nalgene; Thermo Fisher Scientific, Pittsburgh, PA, USA) at a concentration of 10,000 cells per well. Upon adherence, cells were incubated with AuNPs at a nontoxic concentration of $1 \mu \mathrm{g} / \mathrm{mL}$. Cellular uptake of AuNPs or quantum dots of the same size were analyzed with a Zeiss Observer Z1 (Zeiss, Germany).

\subsection{Transmission Electron Microscopy}

Cells were co-incubated with functionalized and non-conjugated AuNPs (at a concentration $100 \mu \mathrm{g} / \mathrm{mL}$ ) for $24 \mathrm{~h}$. Following, incubation cells were washed with PBS, fixed for $1 \mathrm{~h}$ at $4{ }^{\circ} \mathrm{C}$ in $2.5 \%$ glutaraldehyde in $0.1 \mathrm{M}$ cacodylate buffer $(\mathrm{pH}=7.4)$, postfixed in $1 \%$ aqueous $\mathrm{OsO} 4($ for $1 \mathrm{~h})$, dehydrated, and embedded in Araldite-Epon mixture. Sections were assessed employing Zeiss Libra 120 electron microscope (Carl Zeiss, Germany). 


\subsection{Histology and Immunohistochemistry}

Tumors and organs were either dissected following whole-body fixation of mice or fixed in $3.7 \%$ neutral-buffered formaldehyde and embedded in paraffin. Two- $\mu \mathrm{m}$ sections of the organs and tumors were prepared, and the morphology was visualized by standard H\&E staining. For immunohistochemistry, the activity of the endogenous peroxidase was blocked with $1 \%$ hydrogen peroxide and $0.1 \%$ sodium azide. After antigen retrieval in citric acid buffer ( $\mathrm{pH} 6)$ at $100{ }^{\circ} \mathrm{C}$, sections were incubated with anti-Hsp70 antibody cmHsp70.1, followed by horse radish peroxidas (HRP)-labelled secondary rabbit anti-mouse antibody (Dako, Jena, Germany). Diaminobenzidine (Dako) was used as a chromogen. Sections were counterstained with $1 \%$ Mayer's hematoxylin. To visualize the AuNPs by light microscopy, silver-enhancement staining was used according to the manufacturers' protocol (Sigma-Aldrich, Darmstadt, Germany), followed by counterstaining of the nuclei with $0.1 \%$ Nuclear Fast Red solution (Morphisto, Frankfurt a.M., Germany). Slides were digitalized with a digital slide scanner (AT2, Leica, Wetzlar, Germany).

\subsection{Spectral-CT Imaging and Image Acquisition}

Spectral CT images were acquired at a Philips spectral CT scanner, as described before [18]. Briefly, a preclinical spectral photon-counting CT system (Philips Healthcare, Hamburg, Germany) was used to obtain axial scans over $360^{\circ}$ at a beam voltage of $100 \mathrm{kVp}$. For optimal discrimination of the signals of AuNPs, a threshold was set at the k-edge energy of gold.

\subsection{Spectral CT Image-Based Gold Quantification}

Osirix $^{\circledR}$ MD v10.0.5 software (Pixmeo SARL, Bern, Switzerland) was used for analysis. Mean background was measured from several ROIs in the spleen. Gold amounts were calculated over the whole tumor volume $\left(\mu \mathrm{g}\right.$ gold $\left./ \mathrm{mm}^{3}\right)$.

\subsection{Deep Learning-Based Quantification of AuNP Histology}

The biodistribution of silver-stained AuNPs in histological slides was assessed with the help of a deep neural network. Regions of interest in each slide were defined via manual delineation. Slides were subdivided into smaller, slightly overlapping patches of $1000 \times 1000$ pixels to meet memory constraints. In a first preliminary step, AuNP concentrations were segmented with the help of color-channel-specific dynamic thresholding and morphological operations (opening and closing with fixed kernels). Parameters were manually tuned to optimize results for the majority of slides. In a second step, the best resulting binary masks were manually selected and partially manually corrected. In a third step, a deep neural network was trained to segment AuNP concentrations on this basis. In a final step, the trained network was used to derive segmentations of AuNP concentrations for all slide patches. A k-fold rotation of data splits was applied so that the network yields segmentations on data samples that were not used for training, ensuring that the segmentation represents the result of the learned task rather than replicates the threshold-derived training data. This procedure yielded substantially more accurate and consistent segmentations of AuNP concentrations as compared to the preliminary thresholding procedure. Subsequent re-concatenation of slightly overlapping slide patches ruled out boundary effects and double counting. In a postprocessing step, all individual AuNP concentrations were identified via connected-component analysis, allowing to assess their individual sizes.

The deep neural network follows a U-net like architecture and consists of 4 levels of en- and decoding units. Each layer of encoding units doubles the number of feature channels, starting from 16 and ending at 265 at the deepest [16] level. The network was trained for 10 epochs on a training set of ca. 5000 patches. Details of architecture, implementation, and training procedure follow a previously described protocol [34]. 


\section{Conclusions}

Herein, we show that the visualization of tumor cells with AuNPs by addressing membrane Hsp70 is feasible. We present data showing a superior uptake of cmHsp70.1-AuNPs inside Hsp70 membrane-positive tumor cells. Inside the tumor cells, these particles accumulated in the perinuclear region within $24 \mathrm{~h}$. The Hsp70 specificity was shown since unconjugated nanoparticles and nanoparticles conjugated with an irrelevant control antibody were not taken up into Hsp70 membrane-positive tumor cells. Furthermore, Hsp70 knockout tumor cells that do not express Hsp70 in the cytosol and on the plasma membrane showed no uptake of the cmHsp70.1-conjugated nanoparticles [16]. Quantification of the internalized cmHsp70.1-conjugated AuNPs reveals a high sensitivity for the detection of single cells. Experiments are ongoing to study the capability of cmHsp70.1-AuNPs for spectral CT imaging of further Hsp70 membrane-positive and negative tumor models and whether these NPs can be exploited for therapeutic approaches. In the future, these antibody-conjugated AuNPs might be useful for the diagnosis of tumors and for radiotherapeutic interventions.

Author Contributions: Conceptualization, M.A.K. and S.S.; Data curation, M.A.K., M.S., C.W. and S.S.; Formal analysis, M.A.K., C.W., B.H.M., G.M. and S.S.; Funding acquisition, M.A.K., G.M. and S.S.; Investigation, M.S. and S.S.; Methodology, M.A.K., C.W., W.S., W.Z., O.S., R.P., O.B., M.M. and S.S.; Project administration, G.M. and S.S.; Resources, G.M. and S.S.; Supervision, B.H.M., E.J.R., G.M. and S.S.; Validation, M.A.K., C.W., O.S. and S.S.; Visualization, M.A.K., R.P. and S.S.; Writing-original draft, M.A.K. and S.S.; Writing-review and editing, M.A.K., M.S., C.W., W.S., W.Z., O.S., B.H.M., E.J.R., R.P., M.M., G.M. and S.S. All authors were involved in drafting the article or in revising it critically for important intellectual content. All authors have read and agreed to the published version of the manuscript.

Funding: The study was supported by the Russian Foundation for Basic Research (RFBR) according to the research project №20-38-70039 and DFG grant (SFB824/3, STA1520/1-1; ME 3718/5-1), Technische Universität München (TUM) within the DFG funding program Open Access Publishing. Additional financial support was provided by TaGoNaX DFG project №336532926.

Conflicts of Interest: The authors declare no conflict of interest.

\section{Appendix A}

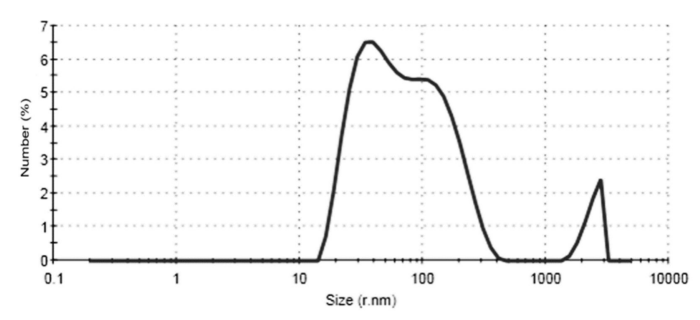

Figure A1. Size distribution of cmHsp70.1-AuNPs after 2 weeks at $4{ }^{\circ} \mathrm{C}$ : Size distribution is given in size by number histogram. 

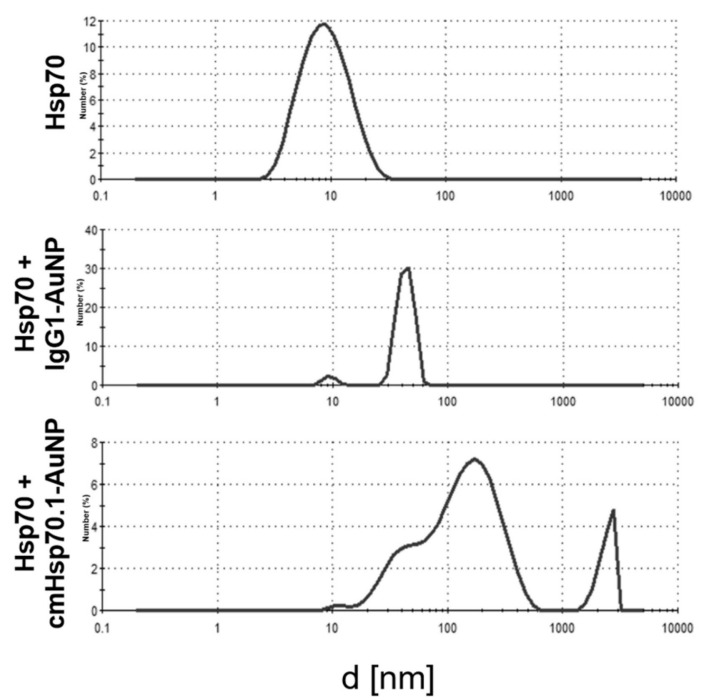

Figure A2. Size distribution of recombinant Hsp70 (upper panel) as well as IgG1-AuNPs (middle panel) and cmHsp70.1-AuNPs (lower panel) following incubation with recombinant Hsp70 for $4 \mathrm{~h}$ : Size distribution is given in size by number histograms.

\section{References}

1. Vanderstraeten, B.; Duthoy, W.; De Gersem, W.; De Neve, W.; Thierens, H. [18F]fluoro-deoxy-glucose positron emission tomography ([18F]FDG-PET) voxel intensity-based intensity-modulated radiation therapy (IMRT) for head and neck cancer. Radiother. Oncol. 2006, 79, 249-258. [CrossRef] [PubMed]

2. Bal, H.; Guerin, L.; Casey, M.E.; Conti, M.; Eriksson, L.; Michel, C.; Fanti, S.; Pettinato, C.; Adler, S.; Choyke, P. Improving PET spatial resolution and detectability for prostate cancer imaging. Phys. Med. Biol. 2014, 59, 4411-4426. [CrossRef]

3. Cormode, D.P.; Naha, P.C.; Fayad, Z.A. Nanoparticle contrast agents for computed tomography: A focus on micelles. Contrast Media Mol. Imaging 2014, 9, 37-52. [CrossRef]

4. Anjomrouz, M.; Shamshad, M.; Panta, R.K.; Broeke, L.V.; Schleich, N.; Atharifard, A.; Aamir, R.; Bheesette, S.; Walsh, M.F.; Goulter, B.P.; et al. Beam profile assessment in spectral CT scanners. J. Appl. Clin. Med. Phys. 2018, 19, 287-297. [CrossRef]

5. Chen, W.H.; Chen, J.X.; Cheng, H.; Chen, C.S.; Yang, J.; Xu, X.D.; Wang, Y.; Zhuo, R.X.; Zhang, X.Z. A new anti-cancer strategy of damaging mitochondria by pro-apoptotic peptide functionalized gold nanoparticles. Chem. Commun. 2013, 49, 6403-6405. [CrossRef]

6. Cormode, D.P.; Roessl, E.; Thran, A.; Skajaa, T.; Gordon, R.E.; Schlomka, J.P.; Fuster, V.; Fisher, E.A.; Mulder, W.J.; Proksa, R.; et al. Atherosclerotic plaque composition: Analysis with multicolor CT and targeted gold nanoparticles. Radiology 2010, 256, 774-782. [CrossRef] [PubMed]

7. Shevtsov, M.; Zhou, Y.; Khachatryan, W.; Multhoff, G.; Gao, H. Recent Advances in Gold Nanoformulations for Cancer Therapy. Curr. Drug Metab. 2018, 19, 768-780. [CrossRef] [PubMed]

8. Sherman, M.; Multhoff, G. Heat shock proteins in cancer. Ann. N. Y. Acad. Sci. 2007, 1113, 192-201. [CrossRef]

9. Stangl, S.; Gehrmann, M.; Riegger, J.; Kuhs, K.; Riederer, I.; Sievert, W.; Hube, K.; Mocikat, R.; Dressel, R.; Kremmer, E.; et al. Targeting membrane heat-shock protein 70 (Hsp70) on tumors by cmHsp70.1 antibody. Proc. Natl. Acad. Sci. USA 2011, 108, 733-738. [CrossRef]

10. Hantschel, M.; Pfister, K.; Jordan, A.; Scholz, R.; Andreesen, R.; Schmitz, G.; Schmetzer, H.; Hiddemann, W.; Multhoff, G. Hsp70 plasma membrane expression on primary tumor biopsy material and bone marrow of leukemic patients. Cell Stress Chaperones 2000, 5, 438-442. [CrossRef] 
11. Stangl, S.; Tontcheva, N.; Sievert, W.; Shevtsov, M.; Niu, M.; Schmid, T.E.; Pigorsch, S.; Combs, S.E.; Haller, B.; Balermpas, P.; et al. Heat shock protein 70 and tumor-infiltrating NK cells as prognostic indicators for patients with squamous cell carcinoma of the head and neck after radiochemotherapy: A multicentre retrospective study of the German Cancer Consortium Radiation Oncology Group (DKTK-ROG). Int. J. Cancer 2018, 142, 1911-1925. [CrossRef] [PubMed]

12. Farkas, B.; Hantschel, M.; Magyarlaki, M.; Becker, B.; Scherer, K.; Landthaler, M.; Pfister, K.; Gehrmann, M.; Gross, C.; Mackensen, A.; et al. Heat shock protein 70 membrane expression and melanoma-associated marker phenotype in primary and metastatic melanoma. Melanoma Res. 2003, 13, 147-152. [CrossRef] [PubMed]

13. Steiner, K.; Graf, M.; Hecht, K.; Reif, S.; Rossbacher, L.; Pfister, K.; Kolb, H.J.; Schmetzer, H.M.; Multhoff, G. High HSP70-membrane expression on leukemic cells from patients with acute myeloid leukemia is associated with a worse prognosis. Leukemia 2006, 20, 2076-2079. [CrossRef] [PubMed]

14. Gehrmann, M.; Radons, J.; Molls, M.; Multhoff, G. The therapeutic implications of clinically applied modifiers of heat shock protein 70 (Hsp70) expression by tumor cells. Cell Stress Chaperones 2008, 13, 1-10. [CrossRef] [PubMed]

15. Stangl, S.; Gehrmann, M.; Dressel, R.; Alves, F.; Dullin, C.; Themelis, G.; Ntziachristos, V.; Staeblein, E.; Walch, A.; Winkelmann, I.; et al. In vivo imaging of CT26 mouse tumours by using cmHsp70.1 monoclonal antibody. J. Cell. Mol. Med. 2011, 15, 874-887. [CrossRef] [PubMed]

16. Gehrmann, M.K.; Kimm, M.A.; Stangl, S.; Schmid, T.E.; Noel, P.B.; Rummeny, E.J.; Multhoff, G. Imaging of Hsp70-positive tumors with cmHsp70.1 antibody-conjugated gold nanoparticles. Int. J. Nanomed. 2015, 10, 5687-5700. [CrossRef]

17. Shevtsov, M.; Stangl, S.; Nikolaev, B.; Yakovleva, L.; Marchenko, Y.; Tagaeva, R.; Sievert, W.; Pitkin, E.; Mazur, A.; Tolstoy, P.; et al. Granzyme B Functionalized Nanoparticles Targeting Membrane Hsp70-Positive Tumors for Multimodal Cancer Theranostics. Small 2019, 15, e1900205. [CrossRef]

18. Schlomka, J.P.; Roessl, E.; Dorscheid, R.; Dill, S.; Martens, G.; Istel, T.; Baumer, C.; Herrmann, C.; Steadman, R.; Zeitler, G.; et al. Experimental feasibility of multi-energy photon-counting K-edge imaging in pre-clinical computed tomography. Phys. Med. Biol. 2008, 53, 4031-4047. [CrossRef]

19. Ashton, J.R.; Clark, D.P.; Moding, E.J.; Ghaghada, K.; Kirsch, D.G.; West, J.L.; Badea, C.T. Dual-energy micro-CT functional imaging of primary lung cancer in mice using gold and iodine nanoparticle contrast agents: A validation study. PLoS ONE 2014, 9, e88129. [CrossRef]

20. Hirsh, M.I.; Hashiguchi, N.; Chen, Y.; Yip, L.; Junger, W.G. Surface expression of HSP72 by LPS-stimulated neutrophils facilitates gammadeltaT cell-mediated killing. Eur. J. Immunol. 2006, 36, 712-721. [CrossRef]

21. Stangl, S.; Tei, L.; De Rose, F.; Reder, S.; Martinelli, J.; Sievert, W.; Shevtsov, M.; Ollinger, R.; Rad, R.; Schwaiger, M.; et al. Preclinical Evaluation of the Hsp70 Peptide Tracer TPP-PEG24-DFO[(89)Zr] for Tumor-Specific PET/CT Imaging. Cancer Res. 2018, 78, 6268-6281. [CrossRef]

22. Stangl, S.; Varga, J.; Freysoldt, B.; Trajkovic-Arsic, M.; Siveke, J.T.; Greten, F.R.; Ntziachristos, V.; Multhoff, G. Selective in vivo imaging of syngeneic, spontaneous, and xenograft tumors using a novel tumor cell-specific hsp70 peptide-based probe. Cancer Res. 2014, 74, 6903-6912. [CrossRef] [PubMed]

23. Cormode, D.P.; Si-Mohamed, S.; Bar-Ness, D.; Sigovan, M.; Naha, P.C.; Balegamire, J.; Lavenne, F.; Coulon, P.; Roessl, E.; Bartels, M.; et al. Multicolor spectral photon-counting computed tomography: In vivo dual contrast imaging with a high count rate scanner. Sci. Rep. 2017, 7, 4784. [CrossRef] [PubMed]

24. Si-Mohamed, S.; Cormode, D.P.; Bar-Ness, D.; Sigovan, M.; Naha, P.C.; Langlois, J.B.; Chalabreysse, L.; Coulon, P.; Blevis, I.; Roessl, E.; et al. Evaluation of spectral photon counting computed tomography K-edge imaging for determination of gold nanoparticle biodistribution in vivo. Nanoscale 2017, 9, 18246-18257. [CrossRef] [PubMed]

25. Schubertova, V.; Martinez-Veracoechea, F.J.; Vacha, R. Influence of ligand distribution on uptake efficiency. Soft Matter 2015, 11, 2726-2730. [CrossRef] [PubMed]

26. Lammers, T.; Kiessling, F.; Hennink, W.E.; Storm, G. Drug targeting to tumors: Principles, pitfalls and (pre-) clinical progress. J. Control. Release 2012, 161, 175-187. [CrossRef] [PubMed]

27. Zhang, X.D.; Wu, D.; Shen, X.; Liu, P.X.; Yang, N.; Zhao, B.; Zhang, H.; Sun, Y.M.; Zhang, L.A.; Fan, F.Y. Size-dependent in vivo toxicity of PEG-coated gold nanoparticles. Int. J. Nanomed. 2011, 6, 2071-2081. [CrossRef] 
28. Alkilany, A.M.; Murphy, C.J. Toxicity and cellular uptake of gold nanoparticles: What we have learned so far? J. Nanopart. Res. 2010, 12, 2313-2333. [CrossRef]

29. Zhang, X.D.; Wu, H.Y.; Wu, D.; Wang, Y.Y.; Chang, J.H.; Zhai, Z.B.; Meng, A.M.; Liu, P.X.; Zhang, L.A.; Fan, F.Y. Toxicologic effects of gold nanoparticles in vivo by different administration routes. Int. J. Nanomed. 2010, 5, 771-781. [CrossRef]

30. Dorsey, J.F.; Sun, L.; Joh, D.Y.; Witztum, A.; Kao, G.D.; Alonso-Basanta, M.; Avery, S.; Hahn, S.M.; Al Zaki, A.; Tsourkas, A. Gold nanoparticles in radiation research: Potential applications for imaging and radiosensitization. Transl. Cancer Res. 2013, 2, 280-291. [CrossRef]

31. Muddineti, O.S.; Ghosh, B.; Biswas, S. Current trends in using polymer coated gold nanoparticles for cancer therapy. Int. J. Pharm. 2015, 484, 252-267. [CrossRef]

32. Hainfeld, J.F.; Dilmanian, F.A.; Zhong, Z.; Slatkin, D.N.; Kalef-Ezra, J.A.; Smilowitz, H.M. Gold nanoparticles enhance the radiation therapy of a murine squamous cell carcinoma. Phys. Med. Biol. 2010, 55, 3045-3059. [CrossRef]

33. Rothammer, A.; Sage, E.K.; Werner, C.; Combs, S.E.; Multhoff, G. Increased heat shock protein 70 (Hsp70) serum levels and low NK cell counts after radiotherapy-Potential markers for predicting breast cancer recurrence? Radiat. Oncol. 2019, 14, 78. [CrossRef]

34. Pan, C.; Schoppe, O.; Parra-Damas, A.; Cai, R.; Todorov, M.I.; Gondi, G.; von Neubeck, B.; Bogurcu-Seidel, N.; Seidel, S.; Sleiman, K.; et al. Deep Learning Reveals Cancer Metastasis and Therapeutic Antibody Targeting in the Entire Body. Cell 2019, 179, 1661-1676. [CrossRef]

(C) 2020 by the authors. Licensee MDPI, Basel, Switzerland. This article is an open access article distributed under the terms and conditions of the Creative Commons Attribution (CC BY) license (http://creativecommons.org/licenses/by/4.0/). 